\title{
Assimilation of Nationwide and Global GPS PWV Data for a Heavy Rain Event on 28 July 2008 in Hokuriku and Kinki, Japan
}

\author{
Yoshinori Shoji, Masaru Kunii, and Kazuo Saito \\ Meteorological Research Institute, Tsukuba, Japan
}

\begin{abstract}
On 28 July, 2008, a local heavy rainfall occurred over the Hokuriku and Kinki districts, in central Japan. A stationary front existed near the heavy rainfall areas, and the atmospheric instability was increased by the inflow of the upper-level cold air.

The operational mesoscale model (MSM) of the Japan Meteorological Agency (JMA) could not predict the heavy rainfall. The comparison of distributions of precipitable water vapor (PWV) between the initial condition of the MSM and the Global Positioning System (GPS) revealed that the MSM initial condition underestimated water vapor in the heavy rainfall areas because of a positional lag of a low-level convergence zone.

Data assimilation experiments of GPS-derived PWV were conducted with JMA's mesoscale 4 dimensional variational assimilation system (Meso 4D-Var). The PWV derived from the nationwide ground GPS network (GPS Earth Observation NETwork: GEONET) improved both the northward position error of the low-level convergence zone and the forecast of the observed rainfall. Moreover, further improvements were obtained when the PWV derived from the GPS stations of the International GNSS Service in East Asia were added.
\end{abstract}

\section{Introduction}

In Japan during the rainy season from June to July, local heavy rainfalls often occur over the Baiu frontal zone. Several studies have suggested the importance of the low-level humid air in the formation of heavy rainfalls and the necessity of an accurate analysis of water vapor under the initial conditions of the numerical model used for predicting heavy rainfalls (e.g., Kato and Aranami 2005).

Since 1994, the Geographical Survey Institute (GSI) of Japan has been deploying a nationwide ground GPS network called GEONET. It covers the entire Japanese archipelago and comprises more than 1,300 ground receivers; the mean distance between these receivers is 15-25 km (Fig. 1). Although the GPS data are primarily used for studying crustal deformation, these data are also useful as water vapor sensors (e.g., Businger et al. 1996). Several studies have shown that the water vapor information retrieved from GEONET has a positive impact on numerical weather prediction (NWP) (e.g., Nakamura et al. 2004; Koizumi and Sato 2004; Seko et al. 2004; Kawabata et al. 2007).

Kato and Aranami (2005) have emphasized the importance of water vapor observation over the ocean. Koizumi and Sato (2004) have combined PWVs derived from ground-based GPS and space-based microwave radiometer (TMI) and showed an improvement in the precipitation forecast. Although GPS stations of GEONET are installed on the ground, by using 4D-Var, GEONETderived PWV can modify the fields of water vapor and other meteorological elements not only on land but also over the ocean. However, it is not easy to assess the adequacy of such modification over the ocean because

Corresponding author: Yoshinori Shoji, Meteorological Research Institute, 1-1 Nagamine, Tsukuba 305-0052, Japan. E-mail: yshoji@mri-jma.go.jp. @2009, the Meteorological Society of Japan. of the lack of contiguous observation. In order to acquire a reliable water vapor field over the ocean, contiguous windward water vapor observation is needed. Studies of PWV retrieval from shipborne GPS observation (e.g., Fujita et al. 2008) present one possible strategy for those purposes.

The International GNSS Service (IGS) operates a continuous global network of ground-based GPS stations for GPS satellite tracking and provides GPS observation data via IGS ftp server. Though the spatial distribution is rather sparse compared to that of the GEONET stations, some of the IGS stations are installed in East Asia (Fig. 1). In this study, we analyze the PWV obtained from IGS stations and assimilate them with GEONET-derived PWV by using Meso 4D-Var in order to validate their usefulness.

The purpose of this study is to examine the impact of PWV derived from GEONET and IGS on mesoscale NWP and demonstrate the validity of GPS observations in Japan and its surrounding areas in the case of heavy rainfall in Japan. Procedures for a PWV analysis are described in Section 2. In Section 3, we present an overview of the heavy rainfall and the characteristics of the GPS-derived PWV. Design of experiments and results of data assimilation are given in Sections 4 and 5. We summarize this study in Section 6.

\section{Analysis of PWV}

\subsection{GPS analysis and $P W V$ retrieval}

On the basis of Shoji (2009), we have performed near real-time (NRT) GPS analysis for both GEONET and IGS stations. Here, the NRT GPS analysis refers to the retrieval of the PWV within several tens of minutes after the observation in order to serve NWP. Currently, the cut-off time of operational Meso 4D-Var is set to $50 \mathrm{~min}$. This NRT procedure requires GPS satellite clock estimation using ground GPS stations to be carried out in

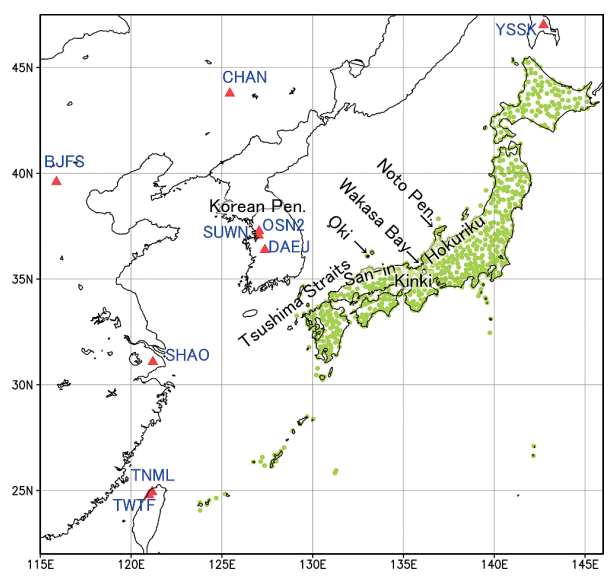

Fig. 1. GPS stations around Japan. Green-filled circles (O): GEONET stations used in the 4D-Var experiments "GEONET" and "GEONET+IGS" and red-filled triangles ( $\boldsymbol{\Delta})$ : IGS stations used in the 4D-Var experiment "GEONET+IGS." Four blue characters near each IGS station denote the IGS station ID. Names of places referred to in this paper are written using black characters. 


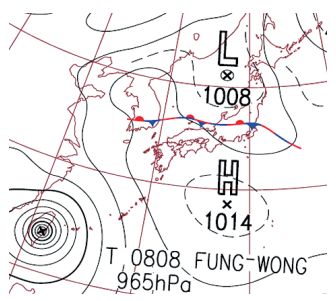

Fig. 2. Surface weather map at 09 JST on 28 July, 2008.
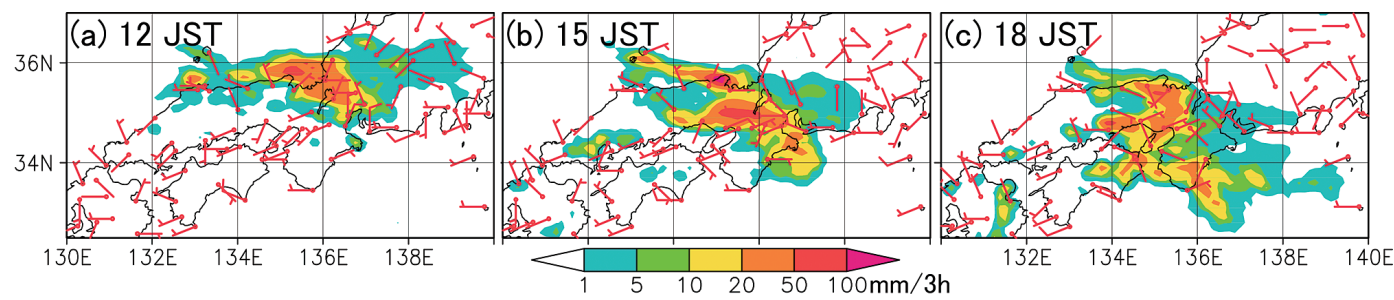

Fig. 3. 3-h accumulated Radar-AMeDAS analyzed rainfall at (a) 12 JST, (b) 15 JST, and (c) 18 JST on 28 July, 2008. Barbs show the observed surface horizontal winds. advance. In order to analyze the clocks of the GPS satellites that are visible from the GPS stations outside Japan, we have expanded the ground GPS station network for a satellite clock analysis from areas surrounding Japan to areas across the globe. Except this modification, we have followed Shoji (2009) and retrieved the Zenith Tropospheric Delay (ZTD) every $10 \mathrm{~min}$.

In order to calculate the PWV from ZTD, we required the values of the pressure and the column mean temperature be weighted by water vapor $\left(\mathrm{T}_{\mathrm{m}}\right)$ at the GPS antenna position. For GEONET sites, we first obtained the pressure and the temperature at the GPS stations by interpolating JMA's surface meteorological observations. Then, $\mathrm{T}_{\mathrm{m}}$ was estimated from the interpolated surface temperature using a linear relation between $T_{m}$ and the surface temperature, which was based on 1-year statistics of radio-sonde observations in Japan. For IGS stations, pressures and $\mathrm{T}_{\mathrm{m}}$ were calculated using MSM first guess because of the lack of surface observation and statistics. We used GSIGEO2000 (Kuroishi et al. 2002) for GEONET and EGM96 (Lemoine et al. 1998) for IGS as a geoid model to calculate the altitude of the GPS stations. Shoji (2009) compared the GEONET-derived PWVs with those obtained from the radio-sonde and calculated the root mean square errors to be $1.6 \mathrm{~mm}$ in winter and $3.4 \mathrm{~mm}$ in summer. Our statistical comparison of IGS-derived PWV with the radio-sonde observation in East Asia also shows a comparable agreement $(2.0 \mathrm{~mm})$.

The PWV of a numerical model is calculated in a rather simple manner from the model variables as

$$
P W V=\frac{1}{g} \int_{p_{s}}^{p_{t}} q d p
$$

where $q, p, p_{t}, p_{s}$, and $g$ are specific humidity, pressure, model top pressure, model surface pressure, and gravitational acceleration, respectively.

\subsection{Height correction}

As Japan has steep mountains and MSM employs smoothed orography for determining the actual terrain surface, there exist large differences between the GPS antenna height and the corresponding MSM surface height in mountainous areas. In order to adjust the differences in the PWVs between the first guess and the GPS, the first guess PWV is interpolated or extrapolated, from the model surface to the actual terrain surface, using a method by Mannoji et al. (1998) as follows:

(1) If the model surface is higher than the actual terrain surface, the model PWV is extrapolated to the actual terrain surface, by assuming that specific humidity between the model and the actual terrain surfaces is equal to that in the lowest model layer.

(2) If the model surface is lower than the actual terrain surface, the model water vapor between the actual terrain and model surfaces is subtracted from the model PWV.

\subsection{Quality control}

The quality check is mainly based on the method proposed by Mannoji et al. (1998). Observed GPS PWV data are discarded if the following conditions are not satisfied:

(1) Absolute value of height difference between the model surface and the actual surface is less than $500 \mathrm{~m}$. (2) Observed GPS PWV is between $1 \mathrm{~mm}$ and $80 \mathrm{~mm}$.

(3) Absolute value of the D-value of PWV is less than 10 $\mathrm{mm}$ after height correction.

As horizontal grid spacing of the Meso 4D-Var system is $20 \mathrm{~km}$, the spatial density of the GEONET stations is higher than that in some places. In order to avoid overfitting, the thinning of GEONET stations is performed so that the spatial density of GPS observation becomes coarser than $20 \mathrm{~km}$. Figure 1 shows the distribution of the 764 GEONET stations and 9 IGS stations used in this study.

Since Meso 4D-Var assimilates observation data with 1-h slots in the 3-h assimilation window, we have evaluated the GPS-derived PWV for each clock hour.

\section{Overview of heavy rainfall and GPS-
derived PWV}

The surface weather map at 09 JST $(+9 \mathrm{~h}$ against UTC) on 28 July, 2008 is shown in Fig. 2. A stationary front was analyzed in the east-west direction across the central part of Honshu Island. There was a cold lowpressure system approximately $500 \mathrm{~km}$ north of the front. The western part of Japan was covered by a highpressure system, and Typhoon 0808 (FUNG-WONG) hit Taiwan. These synoptic patterns suggest inflows of the low-level humid air around the western part of Japan.

Figure 3 shows the 3 -h accumulated Radar-AMeDAS analyzed rainfall, which is estimated by meteorological radars and calibrated using surface rain gauge observations. Before 12 JST, a strong rainfall system was observed along the San-in and Hokuriku districts. The precipitation system developed as it moved southwestward.

Figure 4 shows the time variation in the precipitation system and GPS-derived PWV from 03 to 09 JST on July 28. At 03 JST, a line-shaped precipitation system was located from the northeast through the Noto Peninsula to the southwest (Fig. 4a). The precipitation system developed with time as it moved southward. At 09 JST, the west part of the rain came close to the coast of the San-in region (Fig. 4b). The GPS-derived PWV exceeded by $60 \mathrm{~mm}$ along the San-in district and Wakasa-Bay (Fig. 4c). The change in PWV from 03 JST to 09 JST clearly shows an increase in PWV on the south side of the rainfall system and a decrease on the north side (Fig. 4d). The PWV increase in the San-in district was limited in the coastal region.

This suggests that most of the humid air was concentrated at the lowest level of the troposphere. Further, it is noticeable that in the Korean Peninsula, the PWV decreased at north-side stations (SUWN, and OSN2) while it increased at the south-side point (DAEJ). This contrast may affect the forecast of the numerical model if the PWV derived from the IGS stations is used in 

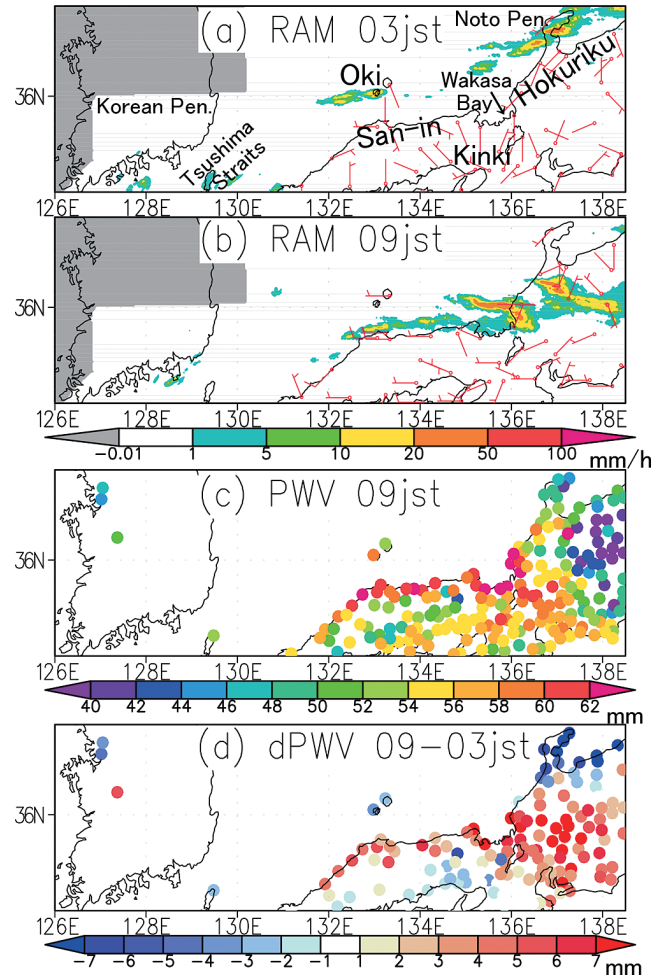

Fig. 4. 1-h accumulated Radar-AMeDAS analyzed rainfall at (a) 03 JST and (b) 09 JST. (c) GPS-derived PWV at 09 JST, and (d) differences in GPS-derived PWV between 09 JST and 03 JST.

addition to that observed from GEONET stations.

\section{Design of experiments}

We used JMA's Meso 4D-Var system for the data assimilation experiments, basically following Nakamura et al. (2004). In this study, we performed the following three continuous assimilation experiments. Each experiment is different in terms of the assimilated observation data as follows:

(1) CNTL

Radio-sonde, synop (surface), ship, buoy, aircraft, wind-profiler, doppler-radar radial wind, wind and PWV fields are retrieved from satellite-based microwave scatterometer/radiometer, Radar-AMeDAS analyzed rainfall, and typhoon bogus data. These data are normally assimilated in the operational Meso 4D-Var.

The observation error of the satellite-based PWV is set to $5 \mathrm{~mm}$. Data thinning with $40 \mathrm{~km}$ is applied. The satellite-based PWV data are discarded in the areas over land, covered by dense cloud, and by precipitation for quality control.

\section{(2) GEONET}

The data used in this experiment are normal data and GPS-derived PWV at GEONET stations. Shoji (2009) has found that the error related to NRT analyzed GPS PWV increases with an increase in the PWV value. In the present study, the observation error for GPS-derived $\mathrm{PWV}$ is set to $5 \mathrm{~mm}$ on the basis of the comparison between GPS and radio-sonde observation. Other settings are the same as those in the case of "CNTL".

\section{(3) GEONET+IGS}

The GPS-derived PWV is added at both GEONET and IGS stations shown in Fig. 1. Other settings are the same as those in the case of "CNTL".

Our target was to improve the forecast at the initial time of 09 JST (28 July, 2008). In each experiment, we performed a pre-run of 30 -h sequential data assimilation from 03 JST (27 July) to 09 JST (28 July) with 3-h assimilation windows. The JMA-nonhydrostatic model (Saito et al. 2007) with a horizontal resolution of $10 \mathrm{~km}$ (10km-NHM) was employed as the forecast model in the numerical prediction after the initial time.

\section{Results}

Figure 5 shows the 3 -h accumulated rainfall distribution predicted by the $10-\mathrm{km}$ NHM for experiments (a) CNTL, (b) GEONET, and (c) GEONET+IGS. The initial time is 09 JST on 28 July, 2008. The experiment "CNTL" (Fig. 5a) predicted neither the development nor the southward movement of the heavy rainfall system shown in Fig. 3. The experiment "GEONET" (Fig. 5b) predicted the line-shaped precipitation system from Wakasa Bay to the Oki islands at FT $=03$, while the system did not develop and did not move southward. The experiment "GEONET+IGS" (Fig. 5c) predicted more intense precipitation around Wakasa Bay at FT = 03 and a southward development of precipitation at FT $=06$. On the whole, we conclude that among these three experiments, "GEONET+IGS" provided the best forecast.
$\mathrm{FT}=03(12 \mathrm{JST})$
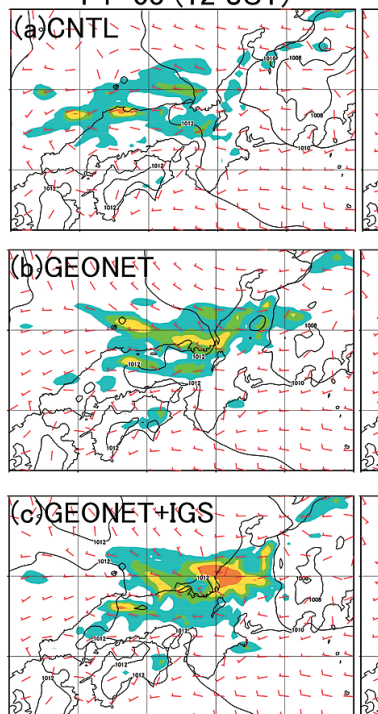

$\mathrm{FT}=06(15 \mathrm{JST})$
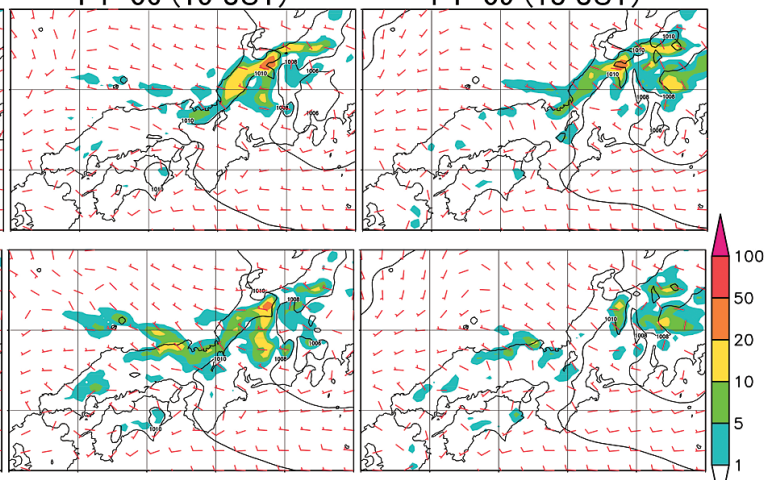

$\mathrm{FT}=09$ (18 JST)

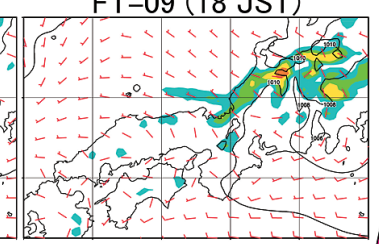

100

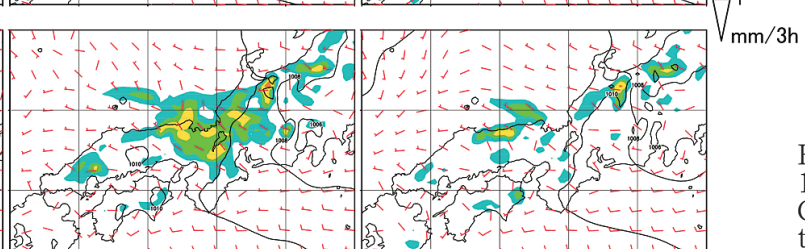

Fig. 5. 3-h accumulated rainfall predicted by $10-\mathrm{km}$ NHM for experiments (a) CNTL, (b) GEONET, and (c) GEONET+IGS. The initial time is 09 JST on 28 July, 2008. 
(a) PWV, Wsfc, Psfc ("CNTL")

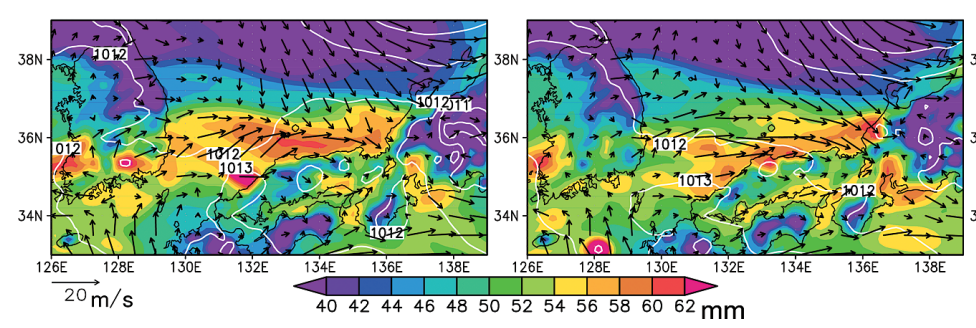

(c) dPWV ("GEONET+IGS"-"GEONET"),

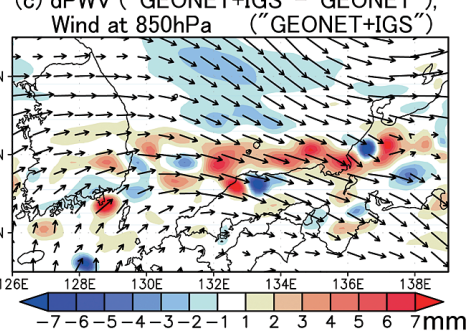

Fig. 6. (a) Initial PWV (shade), surface pressure (contour), and surface wind fields of "CNTL" experiment at 09 JST on 28 July, 2008. (b) Same as (a) except for "GEONET" experiment. (c) Difference in initial field of PWV (shade) between "GEONET+IGS" and "GEONET" at 09 JST on 28 July, 2008. Arrows represent winds at the level of 850 hPa in the case of "GEONET+IGS."

The predicted rainfall is still insufficient at $\mathrm{FT}=9$. In order to elucidate the reason for this insufficiency, DA and NHM model physics need to be investigated further.

Figure 6a describes the initial field of PWV and the surface wind of the "CNTL" experiment at 09 JST on 28 July, 2008. Compared to Fig. 4c, this figure shows PWV overestimation around the Oki islands and its underestimation near San-in seashore. A surface wind convergence zone is formed from Wakasa Bay toward westnorthwest, and the PWV maximum is located around the wind shear line off the north coast of the San-in district. The PWV field in the "GEONET" experiment is shown in Fig. 6b. The overestimation around the Oki islands and the underestimation near the seashore are improved in this experiment. Northerly winds are seen around Wakasa Bay and off the coast of the San-in area. It can be said that through the data assimilation of GPSderived PWV, the weather front was analyzed more properly. In Fig. 6c, we present the differences in PWV fields between "GEONET+IGS" and "GEONET". The arrows in this figure indicate the wind field at $850 \mathrm{hPa}$ level. Eastward extension of positive increment in the PWV that has its origin near "DAEJ" IGS station is clearly observed. In Fig. 4 d, we see a PWV increase at "DAEJ" and a PWV decrease at "SUWN" and "OSN2." The positive increment near "DAEJ" propagated downstream and enhanced the above-mentioned characteristics.

\section{Conclusions}

Data assimilation experiments of the GPS-derived PWV were performed for the Hokuriku and Kinki heavy rainfall that occurred on $28 \mathrm{July}, 2008$. The results strongly support the usefulness of the GEONET-derived PWV. When the PWV from IGS stations in East Asia was additionally assimilated, the forecast improved further. These results suggest the importance of water vapor observations not only in Japan but also in surrounding areas, especially on the windward side.

Some data of the IGS stations around Japan are accessible hourly via anonymous ftp. It means the IGS stations can be used as a global water vapor observation network for the operational NWP. In this paper, we showed a considerable impact of GPS PWV data, though just one case study, and we will pursue further statistical evaluation on the quantitative forecast.

\section{Acknowledgments}

We used GIPSY/OASIS II software package for GPS analysis, which is provided by JPL/NASA. The Geographical Survey Institute kindly provided GEONETobserved RINEX data. Rinex data at IGS sites were obtained from IGS's ftp server.

Part of this study was supported by the Grant-in-Aid for Scientific Research, "Study of data assimilation and evaluation of forecast reliabilities for dynamical prediction of heavy rainfall”, 17110035, 2005-2009.

\section{References}

Businger, S., S. R. Chiswell, M. Bevis, J. Duan, R. A. Anthes, C. Rocken, R. H. Ware, M. Exner, T. VanHove, and F. S. Solheim, 1996: The promise of GPS in atmospheric monitoring. Bull. Amer. Meteor. Soc., 77, 5-18.

Fujita, M., F. Kimura, K. Yoneyama, and M. Yoshizaki, 2008: Verification of precipitable water vapor estimated from shipborne GPS measurements, Geophys. Res. Lett., 35, L13803, doi:10.1029/2008GL033764.

Hollingsworth, A., and P. Loenberg, 1986: The statistical structure of short-range forecast errors a determined from radiosonde data. Part I: The wind field. Tellus, 38A, 111136.

Kato, T., and K. Aranami, 2005: Formation Factors of 2004 Niigata-Fukushima and Fukui heavy rainfalls and problems in the predictions using a cloud-resolving Model. SOLA, 1, 1-4, doi:10.2151/sola.2005-001.

Kawabata, T., H. Seko, K. Saito, T. Kuroda, K. Tamiya, T. Tsuyuki, T. Honda, and Y. Wakazuki, 2007: An assimilation and forecasting experiment of the Nerima heavy rainfall with a cloud-resolving nonhydrostatic 4dimensional variational data assimilation system. $J$. Meteor. Soc. Japan, 85, 255-276.

Koizumi, K., and Y. Sato, 2004: Impact of GPS and TMI precipitable water data on mesoscale numerical weather prediction model forecasts. J. Meteor. Soc. Japan, 82(1B), 453-457.

Kuroishi, Y., H. Ando, and Y. Fukuda, 2002: A new hybrid geoid model for Japan, GSIGEO2000. J. Geodesy, 76, 428-436, doi:10.1007/s00190-002-0266-5.

Lemoine, F. G., S. C. Kenyon, J. K. Factor, R. G. Trimmer, N. K. Pavlis, D. S. Chinn, C. M. Cox, S. M. Klosko, S. B. Luthcke, M. H. Torrence, Y. M. Wang, R. G. Williamson, E. C. Pavlis, R. H. Rapp, and T. R. Olson, 1998: Joint NASA GSFC and the National Imagery and Mapping Agency (NIMA) geopotential model EGM96, NASA/TP- 1998-206861.

Mannoji, N., H. Tada, Y. Hatanaka, R. Ohtani, and I. Naito, 1998: An impact study of presipitable water estimated from ground-based GPS network over Japan. Proceedings of $12^{\text {th }}$ Conference on Numerical Weather Prediction, 77-80.

Nakamura, H., K. Koizumi, and N. Mannoji, 2004: Data assimilation of GPS precipitable water vapor into the JMA mesoscale numerical weather prediction model and its impact on rainfall forecast. J. Meteor. Soc. Japan, 82(1B), 441-452.

Saito, K., J. Ishida, K. Aranami, T. Hara, T. Segawa, M. Narita, and Y. Honda, 2007: Nonhydrostatic atmospheric models and operational development at JMA. J. Meteor. Soc. Japan, 85B, 271-304.

Seko, H., T. Kawabata, T. Tsuyuki, H. Nakamura, K. Koizumi, and T. Iwabuchi, 2004: Impacts of GPS-derived water vapor and radial wind measured by doppler radar on numerical prediction of precipitation. J. Meteor. Soc. Japan, 82(1B), 473-489.

Shoji, Y., 2009: A study of near real-time water vapor analysis using a nationwide dense GPS network of Japan. J. Meteor. Soc. Japan, 87, 1-18.

Manuscript received 9 January 2009, accepted 15 March 2009 SOLA: http://www.jstage.jst.go.jp/browse/sola/ 